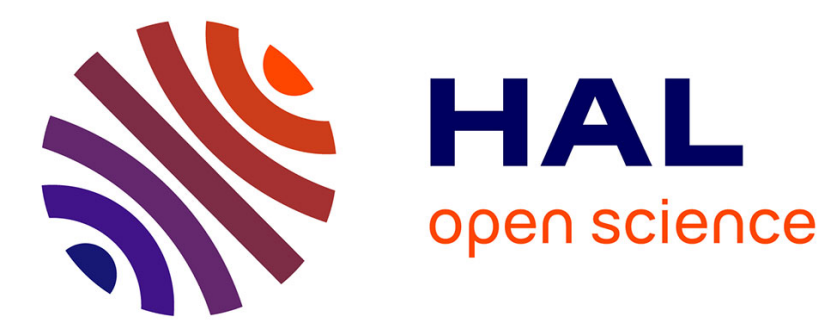

\title{
Personalized Persuasion in Online Advertisements: A Case Study of a Micro-Funding Website
}

\author{
Suleman Shahid, Nicole Heise, Sundas Zaman
}

\section{To cite this version:}

Suleman Shahid, Nicole Heise, Sundas Zaman. Personalized Persuasion in Online Advertisements: A Case Study of a Micro-Funding Website. 16th IFIP Conference on Human-Computer Interaction (INTERACT), Sep 2017, Bombay, India. pp.433-441，10.1007/978-3-319-67687-6_29 . hal-01717218

\author{
HAL Id: hal-01717218 \\ https://hal.inria.fr/hal-01717218
}

Submitted on 26 Feb 2018

HAL is a multi-disciplinary open access archive for the deposit and dissemination of scientific research documents, whether they are published or not. The documents may come from teaching and research institutions in France or abroad, or from public or private research centers.
L'archive ouverte pluridisciplinaire HAL, est destinée au dépôt et à la diffusion de documents scientifiques de niveau recherche, publiés ou non, émanant des établissements d'enseignement et de recherche français ou étrangers, des laboratoires publics ou privés. 


\title{
Personalized Persuasion in Online Advertisements: A Case Study of a Micro-Funding Website
}

\author{
Suleman Shahid ${ }^{1,2}$, Nicole Heise ${ }^{2}$, Sundas Zaman ${ }^{3}$ \\ ${ }^{1}$ Department of Computer Science \\ SBA School of Science and Engineering \\ Lahore University of Management Sciences, Lahore, Pakistan \\ suleman.shahid@lums.edu.pk \\ ${ }^{2}$ Department of Communication and Information Sciences \\ Tilburg center for Cognition and Communication \\ Tilburg University, Tilburg, The Netherlands \\ nicole.heisedive.com \\ s.shahid@uvt.nl \\ ${ }^{3}$ Department of Computing, Heriot Watt University \\ Dubai, United Arab Emirates \\ sz35@hw.ac.uk
}

\begin{abstract}
This study evaluates the effect of different persuasive communication principles in (online) communication on the attitude and purchasing behaviour of (prospective) customers. It also explores how (prospective) customers' personality effect the way they react to different implementations of persuasive principles. The research was conducted using an online questionnaire, and a nonprofit micro funding website was used as a case study. Our results reveal that persuasive communication is more effective than the neutral communication, and it positively influences the behaviour of customers (prospective donators). Furthermore, we found a couple of personality traits that interact with several implementations of the persuasive principles.
\end{abstract}

Keywords: Online personalization; persuasion; web design; micro funding; advertisement; online marketing

\section{Introduction}

Online personalization is a new phenomenon, applied to websites of organizations that want to offer tailored content and services to their (prospective) customers, based on the data gathered from their customers' interactions with different services [10]. The design of an interactive system, such as a website, should be based upon an understanding of the cognitive abilities of the website users [4]. In case of a typical ecommerce website, these users are actually the (prospective) customers of an organization and it is important to design an optimized user experience. For designing a satisfying online experience, it is not only important to pay attention to visual details and information architecture [7] but also to the relevancy of contents [5]. 
Recent research has shown that theory-driven and personality-targeted user interface design can be more effective than design applied to the whole population [9]. Moreover, it has been shown that personalized contents are more useful, make (prospective) customers more willing to explore the online contents further, reduce their information overload, and actually assist them in making decisions [11]. Recent studies on crowdfunding has also shown that language used in the crowdfunding project has surprising predictive power (accounting for $58.56 \%$ of the variance) around successful funding [8]. Organizations also use this form of personalized communication to achieve specific persuasive goals (e.g. using different customization strategies to satisfy information needs or increase attention). This personalized online communication intends to bring cognitive change in (prospective) customers [9], changing the mental state of a customer who learns something about the organization, its goals, its offers, and forms a particular attitude towards the organization. Mostly, these personalized (persuasive) communication messages are designed to produce a desirable impact on the customers' behaviour i.e. change their attitude and purchasing behaviour. The online communication (and use of persuasive messages) of an organization towards the (prospective) customer can be personalized based on what each one might be interested in, or is more sensitive to, in terms of promotion of products, services, and argumentation.

In this research, we evaluate the extent to which the personalized and persuasive communication is preferred over the neutral communication by (prospective) customers. We also explore how different implementations of the persuasive communication principles, as proposed by Cialdini [2], have a different effect on these customers. Cialdini found six persuasive communication principles for influencing and persuading that assist in decision-making: reciprocity (principle that assumes that people are inclined to return the favour to other people, even if unrequested, and compensate to equal proportions), social proof (principle that assumes that that people like to do or think like other people that are similar to them, especially when being uncertain), commitment and consistency (principle that assumes that people want to live in accordance with their words, attitudes and actions, especially in the eyes of other people, and will therefore do what they say they will do to avoid inconsistencies), and sympathy (principle that assumes that people will do things for other people that they like and think of as sympathetic). In this study, the principles authority and scarcity were not used since they did not seem to apply to the concept non-profit organizations and micro funding projects.

As suggested by many other researchers [5], persuasive principles can be implemented in various ways. This study attempts to compare different implementations of persuasive principles for finding out the effective and ineffective ones, in the context of a non-profit micro funding website. It is important to realize that all persuasive principles might not be suitable for all customers. As previously suggested by Ajzen [1], the individual differences of (prospective) customers such as personality traits influence their attitude and purchasing behaviour. Therefore, it is highly likely that different customers would appreciate different persuasive principles. This research evaluates whether the personality traits, based on the Big Five personality set [3], of (prospective) customers, influence the effectiveness of certain persuasive communication principles in terms of (purchasing) behaviour. 
Unlike a number of previous studies where researchers focused on a typical ecommerce website, in this study, we focus on the website of a non-profit micro funding organization named Kiva Microfunds. Kiva Microfunds is a non-profit organization that lends small amounts of money to different entrepreneurs all around the world and practices mainly a neutral communication style. Micro funding websites for a social cause are growing rapidly, and it is important to know how the visitors of such nonprofit websites react to persuasive communication.

\section{Methodology}

This research, as shown in Table 1, utilizes a subject design with five conditions. The independent variables were (1) the 5 personality traits extraversion, agreeableness, conscientiousness, neuroticism and intellect / imagination on which the respondent scores low or high, (2) the 5 persuasive principles reciprocity, social proof, commitment \& consistency, sympathy, and neutral, that might or might not influence the respondent, and (3) the attitude and behaviour of the respondents towards the topic of the online advertisement. The independent variables were (1) the type of project in the online advertisement that is shown to the respondent and (2) the kind of implementation of the persuasive principle that is shown to the respondent.

To be able to investigate whether different implementations of the same persuasive communication principles have an effect on the attitude and/or purchasing behaviour of (prospective) customers, 5 different groups were created (for randomization) as shown in Table 1. Respondents saw the same online advertisements of 5 different micro funding projects, and each persuasive principle integrated in the online advertisements (including one neutral advertisement) in a randomized order. However, each respondent saw different implementations of each persuasive principle.

Table 1. The design of the 5 groups and 25 online advertisements with different implementations of each persuasive principle.

\begin{tabular}{|c|c|c|c|c|c|}
\hline $\begin{array}{l}\text { Persuasive } \\
\text { principles }\end{array}$ & $\begin{array}{l}\text { Project } 1 \\
\text { Cameroon }\end{array}$ & $\begin{array}{l}\text { Project } 2 \\
\text { Philippines }\end{array}$ & $\begin{array}{l}\text { Project } 3 \\
\text { Indonesia }\end{array}$ & $\begin{array}{l}\text { Project } 4 \\
\text { Pakistan }\end{array}$ & $\begin{array}{l}\text { Project } 5 \\
\text { Peru }\end{array}$ \\
\hline Reciprocity & Ad 1 & Ad 6 & Ad 11 & Ad 16 & Ad 21 \\
\hline Social proof & Ad 2 & Ad 7 & Ad 12 & Ad 17 & Ad 22 \\
\hline $\begin{array}{l}\text { Commitment } \\
\& \text { consistency }\end{array}$ & Ad 3 & Ad 8 & Ad 13 & Ad 18 & Ad 23 \\
\hline Sympathy & Ad 4 & Ad 9 & Ad 14 & Ad 19 & Ad 24 \\
\hline Neutral & Ad 5 & Ad 10 & Ad 15 & Ad 20 & Ad 25 \\
\hline
\end{tabular}

\subsection{Stimuli - creating online advertisements}

25 online advertisements were developed by a professional web designer, based on the current template of the micro funding projects of Kiva Microfunds. Existing projects (individual projects with clear description and goals) from 5 different countries and 5 different work fields were carefully selected. The layout and the content of the online 
advertisement developed for this research remained very consistent and similar to the original online advertisements of Kiva Microfunds. Adaptations were made in order to exclude unnecessary influencing and persuading communication elements, other than the manipulated persuasive profiles (the confounding factors).

Persuasive principles were implemented in four different parts of the online advertisements, marked red in Figure 1. Five implementations for each persuasive principle were designed, and after the manipulation check in a pilot, the best implementations were used in the final stimuli.

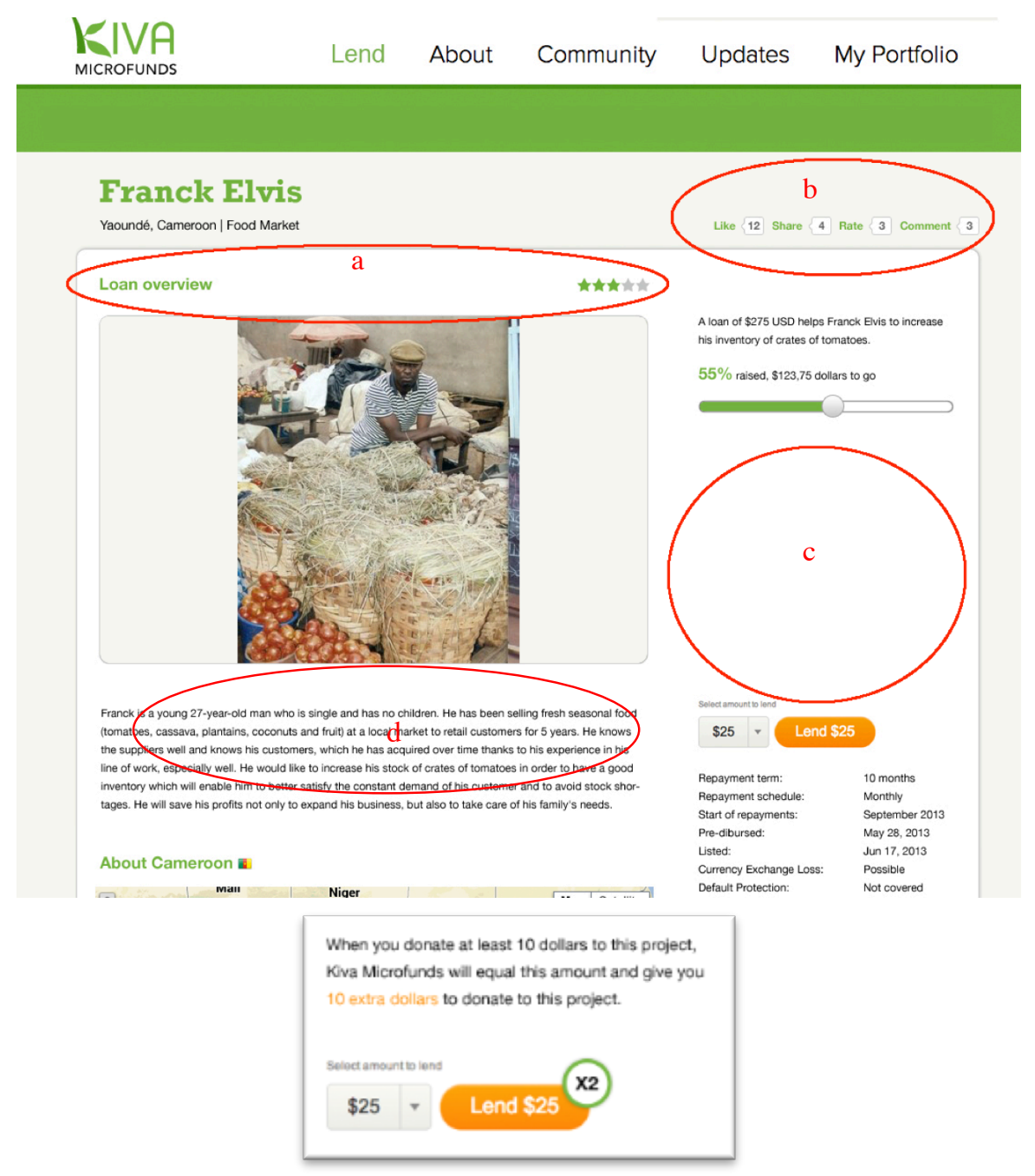

Fig 1: Left to right, top to bottom. Top part of the online advertisement of a project from Kiva Microfunds (highlighting three areas where persuasive principles were added - areas a, b, d), bottom part of the advertisement, one of the most effective implementation (persuasive principle reciprocity) implemented in the area c. 
The implementations of the reciprocity advertisements contain persuasive communication where the respondent is receiving something back from the organization Kiva Microfunds e.g. a message like this "when you donate at least 10 dollars to this project, Kiva will equalize this amount and will give you 10 extra dollars to donate to this project" (figure 1 - area c), receive a gadget for free, get an incentive like a free gift card that can be used to get familiar with contributing.

The implementations of the social proof advertisements contain content that comes from contributors who rated or reviewed the project displayed in the advertisement e.g. Other evaluator/contributor has rated this project as 5 (figure 1 - area a), your Facebook friend has recommended a particular project (figure 1 - area b), this project is a popular one and has been viewed by other visitors many times.

The implementations of the sympathy advertisements contain contents that directly connect contributor with the person in the advertisement and the contributor feels that they both have something in common e.g. a very personal text aimed at the reader instead of using the third person form i.e. Fredrick is from Cameron, use of the first person form i.e. I am Oranci, 32 years old women from Indonesia and I need your support in opening a grocery store (figure 1 - area $\mathrm{d}$ - implemented as a project description), seeing that a relative or good friend has already appreciated and contributed to the project or recommendation from other similar (to your profile) contributors.

The implementations of the commitment \& consistency advertisements contain content where the visitor is shown a certain commitment that he/she has made to Kiva Microfunds e.g. showing a message that in past you have rated with project very high and shared it with 5 friends (figure 1 - area $b$ ), you have liked the project, placing a comment with a positive statement about the project and intention to contribute. The neutral advertisements contained information about the project according to the normal standards for an advertisement of Kiva Microfunds without integrated stimuli.

\subsection{Procedure}

An online questionnaire was conducted and it consisted of 4 different blocks:

(1) Questions about charity/donation habits of participants

(2) Introduction and personality questions (Big 5 personality traits)

(3) Random distribution to 1 of the 5 groups containing 5 online advertisements, where attitude and behaviour (the distribution of 100 dollars to minimum 2 micro funding projects) was measured, and

(4) Demographic and other information.

The questionnaire had a duration time of 10 to 20 minutes. Each of the 5 groups (created for the sake of randomization) saw the advertisements in a different order, based on the persuasive principle that was implemented. A respondent in group 1 saw advertisements $1,7,13,19$, and 25, a respondent in group 2 saw advertisements 6,12 , 18,24 , and 5, a respondent in group 3 saw advertisements $11,17,23,4$, and 10, a respondent in group 4 saw advertisements 16, 22, 3, 9, and 15, and a respondent in group 5 saw advertisements $21,2,8,14$, and 20. In total, 139 respondents $(M=65$, 
$\mathrm{F}=74$ ), recruited via the university pool, were used for analysis. We ignored all others participants who did not complete the survey.

Furthermore, only those participants who donated to a charity in past or were willing to do so in the near future were allowed to participate. Those who didn't meet this criteria (around 200 respondents) were immediately directed to the 'thank you' page. The respondents were randomly distributed and equally divided among these 5 groups, with 28 respondents in group 1,29 respondents in group 2, 28 respondents in group 3, 27 respondents in group 4, and 27 respondents in group 5. A chi-square analysis showed that the demographics were equally divided between these groups (gender $\left(\chi^{2}(4)=8.72\right.$, $\mathrm{p}=.07)$, age $\left(\chi^{2}(20)=22.98, \mathrm{p}=.29\right)$ and education $\left.\left(\chi^{2}(16)=18.13, \mathrm{p}=.32\right)\right)$.

\section{Results}

Firstly, we analysed the behaviour data (the distribution of the 100 dollars among the micro funding projects, for which we created variables per project and per persuasive principle). Then, we analysed personality data. Each respondent answered 4 questions per personality trait, indicating the extent to which they relate themselves to the statement on a 7-point Likert scale (1 meaning that they cannot relate, 7 meaning that they can relate). The mean scores of respondents on the personality traits were divided in low (lowest until 4.25) or high (4.26 through highest) categories. In this paper we will only report the results of the behaviour and personality analysis, the attitude results will be presented in another avenue.

In paired-samples, t-test with Bonferroni correction (adjusted alpha levels), the neutral online advertisements were found to have received significantly less contributions from the respondents as opposed to the advertisements that contained persuasive communication elements (reciprocity $(\mathrm{t}(138)=-4.40, \mathrm{p}<.00)$, social proof $(\mathrm{t}(138)=2.68$, $\mathrm{p}<.01)$, commitment and consistency $(\mathrm{t}(138)=-3.47, \mathrm{p}<.001)$, sympathy $(\mathrm{t}(138)=-2.88$, $\mathrm{p}<.005)$ ), as shown in Figure 2 (the mean contributed amount of money, between 0-100 dollars, and the standard deviation). A two-way ANOVA with repeated measures was used to measure the 5 different persuasive principles for each of the groups to which respondents were assigned.

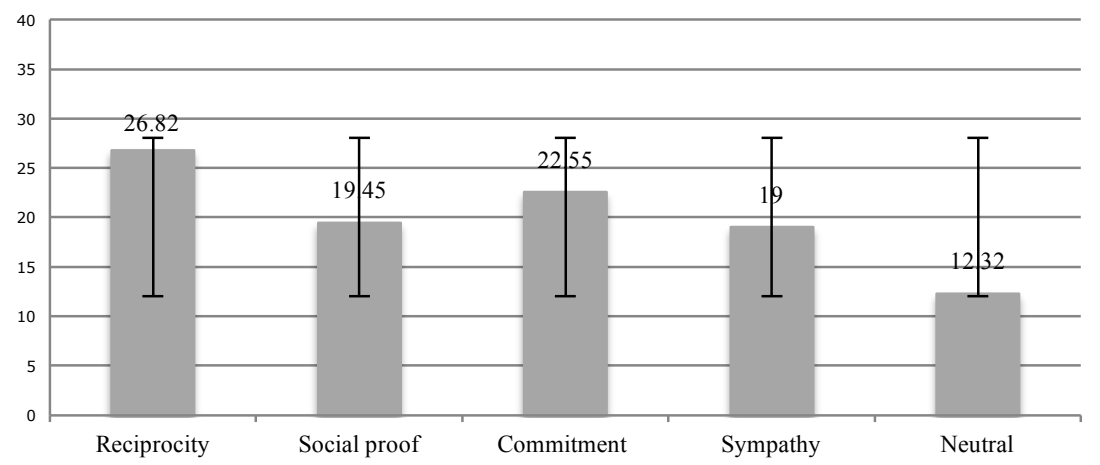

Fig 2. Behaviour $(\mathrm{M})$ of respondents from $0-100$ dollars displayed per persuasive profile. 
The persuasive principle reciprocity was overall found to be the most effective persuasive principle because it received the highest amount of contributed money. The integrated implementations for reciprocity that were found to be working most effectively (based on the amount of money received for particular advertisement) were both related to money: when respondents were said to 'receive a free gift card of 10 dollars' $(\mathrm{M}=36.82, \mathrm{SD}=15.58)$ and when respondents were said to 'receive double amount of dollars for free to spend on the project' (M=35.52, SD=30.98).

The persuasive principle commitment \& consistency was found to be the second most effective principle. The integrated implementations for commitment \& consistency that were found to be working most effectively were: when respondents were shown that they (and a few others) have 'placed a comment' $(M=34.46, \mathrm{SD}=29.45)$ and 'liked a project' $(M=29.07, \mathrm{SD}=29.78)$. The persuasive principle social proof was found to be the third most effective principle. The implementation, "positive evaluations (comments)' and 'ratings (stars) by friends' was found to be the most effective integrated implementation ( $M=28.62, S D=29,46)$. The persuasive principle sympathy was the least effective one (still much better than the neutral). The most effective implementation was 'a good friend contributed to the project' $(M=23.93, S D=21.49)$.

Additionally, a two-way ANOVA with repeated measures was conducted to measure the effect of personality traits on behaviour. We found two interesting results here. First, for the personality trait conscientiousness, the Levene's test showed a significant effect for the respondents who contributed to advertisements that contained the persuasive communication principle reciprocity $(\mathrm{F}(1,137)=7.67, \mathrm{p}<.01)$, as shown in $3 \mathrm{a}$ and second, for the personality trait agreeableness, the Levene's test showed a significant effect for the respondents who contributed to advertisements that contained the persuasive communication social proof $(\mathrm{F}(1,137)=5.59, \mathrm{p}<.05)$, as shown in Figure $3 \mathrm{~b}$.
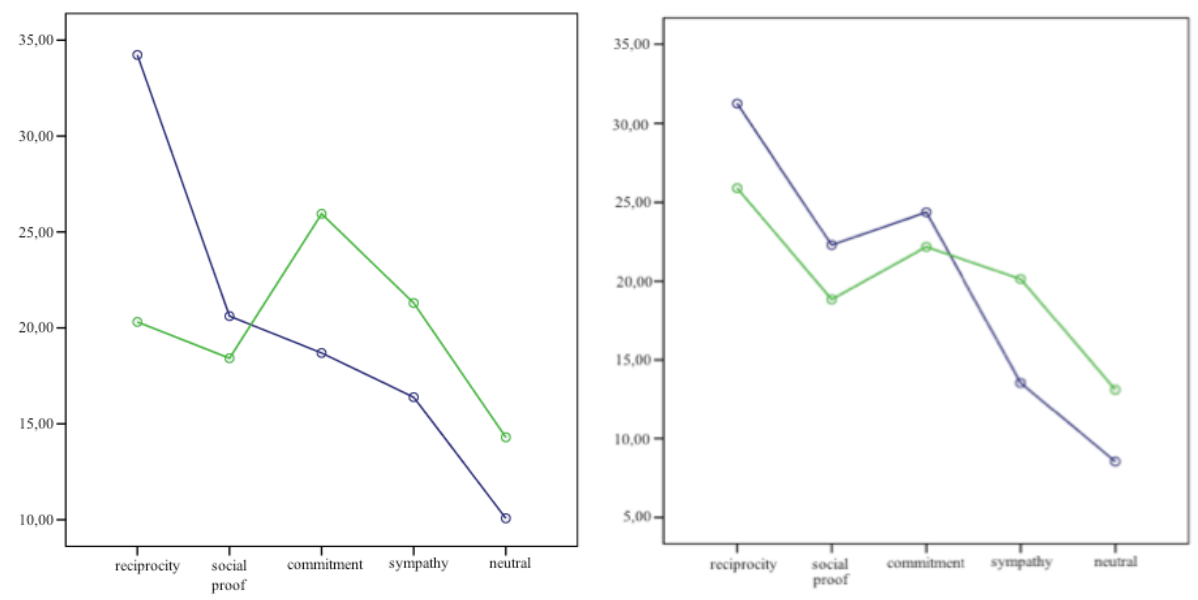

Fig 3a (left). Results of the personality trait conscientiousness (blue $=$ low score, green $=$ high score), effect per persuasive principle - $\mathbf{3 b}$ (right) Results of the personality trait agreeableness (blue $=$ low score, green $=$ high score), effect per persuasive principle 


\section{Discussion and conclusion}

In this paper, we evaluated the effect of different persuasive communication principles, embedded in a non-profit micro funding website based on the attitude and purchasing behaviour of (prospective) customers. Our preliminary results are quite interesting and have clearly shown the potential of persuasive communication (as it seems better than the neutral communication) for a non-profit micro funding website. Micro funding websites designed for a social cause are different from typical ecommerce websites and implementation of persuasive principles also requires a different approach. The correct implementation of persuasive communication principles can lead to more contributions in micro funding projects. For example, our results show that reciprocity was one of the most successful persuasive principle, which is inline with the recent previous work where it has been shown that principle of Reciprocity is one of the top predictors of successful funding [8]. Our results also show an interesting interplay between personality traits and different persuasive principles. For example, the interaction between the personality trait conscientiousness and the persuasive principle reciprocity shows that customers with a high need for cognitive processing will go through the central route of persuasion [10], meaning that they will carefully look at the argumentation within the online advertisements and consider the best options on merit (as seen in figure 3) [2,6].

In the case of reciprocity, either the receiver was getting extra benefits, or the contributor was getting something in return. We also found that people pay attention to different evidences that help them in establishing the merit of the project (whether the project is worth a contribution or not). They are mainly able do this by looking at evaluations and ratings given by other contributors, especially by the ones they know (social proof). This principle correlates with the personality trait agreeableness. This is understandable because people with this trait are sympathetic and good-natured and they listen to what others think and how others feel towards a project [1] (leading them to the peripheral route of persuasion).

Our results also show that the principle commitment and consistency also had an overall high effect. This finding is inline with previous findings where it has been shown that openly committing to a project helps people to stay consistent [2].

\section{Future work}

In future, we not only aim to collect more data from people belonging to difference cultural backgrounds and socio-economic profiles. Moreover, for this study, we only chose participants who had contributed to such projects in past or were willing to do so in near future. In the first round of survey $2 / 3$ of the respondents did not fulfil this tough criterion. In future, it would be interesting to allow all participants to complete the survey and then see how two groups (the one who contributed in past and the one who never contributed) differ from each other.

In the next round, we will also analyse the attitude of people toward different persuasive principles and projects. We will also examine the effectiveness of specific implementations of persuasive principles in detail. For example, in this study, mainly 
one implementation of Sympathy principle worked and the one that worked looked similar to the implementation of social proof.

\section{References}

1. Ajzen, I.: Attitudes, personality, and behavior. McGraw-Hill International (2005)

2. Cialdini, R. B.: Influence. $5^{\text {th }}$ edition. Boston: Pearson (2009)

3. Donnellan, M.B., Oswald, F.L., Baird, B.M., \& Lucas, R.E: The mini-IPIP scales: Tiny-yeteffective measures of the Big Five factors of personality. Psychological Assessment, 18, (2006) 192-203.

4. Esgate, Anthony \& Groome: An Introduction to Applied Cognitive Psychology. Psychology Press, New York (2005)

5. Garrett, J. J.: Elements of User Experience, The: User-Centered Design for the Web and Beyond. Pearson Education (2010)

6. Kaptein, M., \& Eckles, D.: Selecting effective means to any end: Futures and ethics of persuasion profiling. In Persuasive technology (pp. 82-93). Springer (2010)

7. Kramer, J., Noronha, S., \& Vergo, J.: A user-centered design approach to personalization. Communications of the ACM, 43(8), (2000) 44-48.

8. Mitra, T., and Gilbert, E.: The language that gets people to give: Phrases that predict success on kickstarter. In the ACM conference on Computer Supported Cooperative Work (CSCW), (2014)

9. Nov, O., Arazy, O., López, C., \& Brusilovsky, P.: Exploring personality-targeted UI design in online social participation systems. In the ACM conference on on Human Factors in Computing Systems (CHI), (2013).

10. Pappas, I. O., Giannakos, M. N., Kourouthanassis, P. E., \& Chrissikopoulos, V.: Assessing Emotions Related to Privacy and Trust in Personalized Services. In Collaborative, Trusted and Privacy-Aware e/m-Services. Springer Berlin Heidelberg (2013) 38-49.

11. Tam, K. Y., \& Ho, S. Y.: Web personalization as a persuasion strategy: An elaboration likelihood model perspective. Information Systems Research, 16(3), (2005) 271-291 